\title{
Cerium Chloride as a Histochemical Marker of Hydrogen Peroxide in Reperfused Ischemic Hearts
}

\author{
Marshal Shlafer*†, Kimberly Brosamer*, John R. Forder*, \\ Richard H. Simon†, Peter A. Ward $\S$ and Cyril M. Grum; \\ Departments of * Pharmacology, † Surgery (Section of Thoracic Surgery), \\ $\ddagger$ Internal Medicine (Division of Pulmonary $\mathbb{G}^{\circ}$ Critical Care Medicine), and $\$$ Pathology, \\ The University of Michigan Medical School, Ann Arbor, MI 48109, USA
}

(Received 20 March 1989, accepted in revised furm 20 September 1989)

\begin{abstract}
M. Shlafer, K. Brosamer, J. R. Forder, R. H. Simon, P. A. Ward and G. M. Grum. Cerium Chloride as a Histochemical Marker of Hydrogen Peroxide in Reperfused Ischemic Hearts. Joumal of Molecular and Cellular Cardiology (1990) 22, 83-97. Hydrogen peroxide $\left(\mathrm{H}_{2} \mathrm{O}_{2}\right)$ has been implicated in cardiac damage due to ischemia and reperfusion. We adapted an electron microscopic, histochemical method for demonstrating $\mathrm{H}_{2} \mathrm{O}_{2}$ produced by isolated cells to isolated, buffer-perfused rabbit hearts. The method involves formation of an electron-dense precipitate when $\mathrm{H}_{2} \mathrm{O}_{2}$ reacts with cerium chloride $\left(\mathrm{CeCl}_{3}\right)$. We perfused hearts retrograde via the aorta with well-oxygenated bicarbonatc-buffered solution, followed by one in which bicarbonate was replaced with imidazole (IPSS) to prevent precipitation of bicarbonate and $\mathrm{CeCl}_{3}$. Some hearts were made globally ischemic $\left(30 \mathrm{~min}, 37^{\circ} \mathrm{C}\right)$, reperfused 5 min with well-oxygenated IPSS containing $1 \mathrm{~mm} \mathrm{CeCl}_{3}$, then processed for electron microscopy. Others were perfused with IPSS containing catalase $(300 \mathrm{U} / \mathrm{ml})$ or albumin before ischemia and upon reperfusion, followed by $\mathrm{CeCl}_{3}$ administration. Nonischemic control hearts perfused with IPSS ( \pm catalase) were also studied. Electron micrographs were assessed visually and by computer for precipitate localization and amount. There was abundant precipitate on the luminal face of the coronary vascular endothelium in ischemic-reperfused, cerium-treated hearts, including those treated with albumin. There was significantly less in reperfused catalase-treated or nonischemic control hearts. X-ray microbeam analysis of the endothelial precipitate indicated the presence of Ce. This appears to be the first visual demonstration of a $\mathrm{CeCl}_{3}-\mathrm{H}_{2} \mathrm{O}_{2}$-dependent reaction product in intact isolated ischemic hearts. The data indicate that at the time of reperfusion some $\mathrm{H}_{2} \mathrm{O}_{2}$ is accessible to the vascular space, and that its amount can be reduced by perfused catalase. Further modifications this technique may be useful for assessing the sites and pathways by which $\mathrm{H}_{2} \mathrm{O}_{2}$ is generated by hearts or other buffer-perfused organs subjected to stresses such as ischemia or hypoxia.
\end{abstract}

KeY WoRDs: Cerium; Cytochemistry; Electron microscopy; Hydrogen peroxide; Ischemia; Oxygen radicals; Reperfusion.

\section{Introduction}

Many studies of blood- and buffer-perfused hearts subjected to ischemia or hypoxia have led to the conclusion that cytotoxic oxygen metabolites, including $\mathrm{H}_{2} \mathrm{O}_{2}$, are produced, especially upon reperfusion or reoxygenation. Such oxidants are thought to contribute to cardiac damage. Most data to support these general hypotheses have been obtained from experiments showing that exogenous interventions that reduce oxidant generation or reactivity can reduce contractile or biochemical manifestations of damage. Electron spin resonance and biochemical techniques applied to intact hearts provide more direct support for free radical generation, but they still make it difficult to localize sites of oxidant production or the sites that diffusible oxidants such as $\mathrm{H}_{2} \mathrm{O}_{2}$ might reach.

Previously we tested the ability of superoxide dismutase (SOD), catalase, allopurinol, or deferoxamine, to reduce creatine kinase loss from hypoxic/reoxygenated rabbit hearts (Myers et al., 1985), or contractile dysfunction in globally ischemic and reperfused hearts (Shlafer et al., 1982a, b; Myers et al., 1986). Of the interventions tested singly by us (Myers $e t$ al., 1985, 1986), only catalase gave some evidence of protection in both models, so we postulated that $\mathrm{H}_{2} \mathrm{O}_{2}$ played a role in the 
damage process. Catalase is a large protein. When perfused, it should be restricted mainly to the vascular space and should be accessible there to the $\mathrm{H}_{2} \mathrm{O}_{2}$ which it degrades. We now report visual evidence of $\mathrm{H}_{2} \mathrm{O}_{2}$ formed in isolated, buffer-perfused hearts, and that it is present at such catalase-accessible sites.

Cerium chloride was used as the histochemical probe because it reacts with $\mathrm{H}_{2} \mathrm{O}_{2}$ to form an electron-dense precipitate (Briggs et al., 1975), and this reaction can be inhibited by catalase. An isolated, buffer-perfused rabbit hcart model was used to eliminate circulating neutrophils (Lucchesi and Mullane, 1986) and xanthine oxidase (Grum et al., 1986, 1987; Downey et al., 1987) as potential sources of $\mathrm{H}_{2} \mathrm{O}_{2}$.

\section{Materials and Methods}

The overall protocol from heart perfusion to postfixation processing is summarized in Figure 1. We used healthy New Zealand White rabbits weighing approximately $1.5 \mathrm{~kg}$. Animal procurement, care, and use followed all applicable guidelines. The protocol for heart isolation, perfusion, and instrumentation has been described previously (Myers et al., 1986); modifications are noted below. Hearts were initially perfused retrogradely via the aorta for $20 \mathrm{~min}$ with a phosphate-free bicarbonate-buffered physiologic saline solution (BPSS; $37^{\circ} \mathrm{C}, 75 \mathrm{~mm} \mathrm{Hg}$ perfusion pressure, equilibrated via direct bubbling with $95 \% \mathrm{O}_{2}+5 \% \quad \mathrm{CO}_{2}$ through fritted glass). This was to ensure that baseline coronary flow and contractile function (measured with a left intraventricular balloon) were comparable to values obtained in previous studies in which this perfusate was used (Shlafer et al., 1982a, b; Myers et al., 1985, 1986; Grum et al., 1987; Shlafer et al., 1982a, b; Myers et al., 1985, 1986; Grum et al., 1987). The composition of the BPSS was (mM): $\mathrm{NaCl} 118, \mathrm{KCl} 4$, $\mathrm{NaHCO}_{3} 25, \mathrm{MgCl}_{2}$ 1.2, $\mathrm{CaCl}_{2}$ 2.4, D-glucose 11.

Since the BPSS contained bicarbonate, which precipitates with $\mathrm{Ce}$, the perfusate was switched to one in which bicarbonate was omitted, and $15 \mathrm{~mm}$ imidazole (IPSS) was used for buffering. Sodium concentration and osmolality were restored by adding an additional $25 \mathrm{mmol} / 1 \mathrm{NaCl}$. Imidazole was selec-

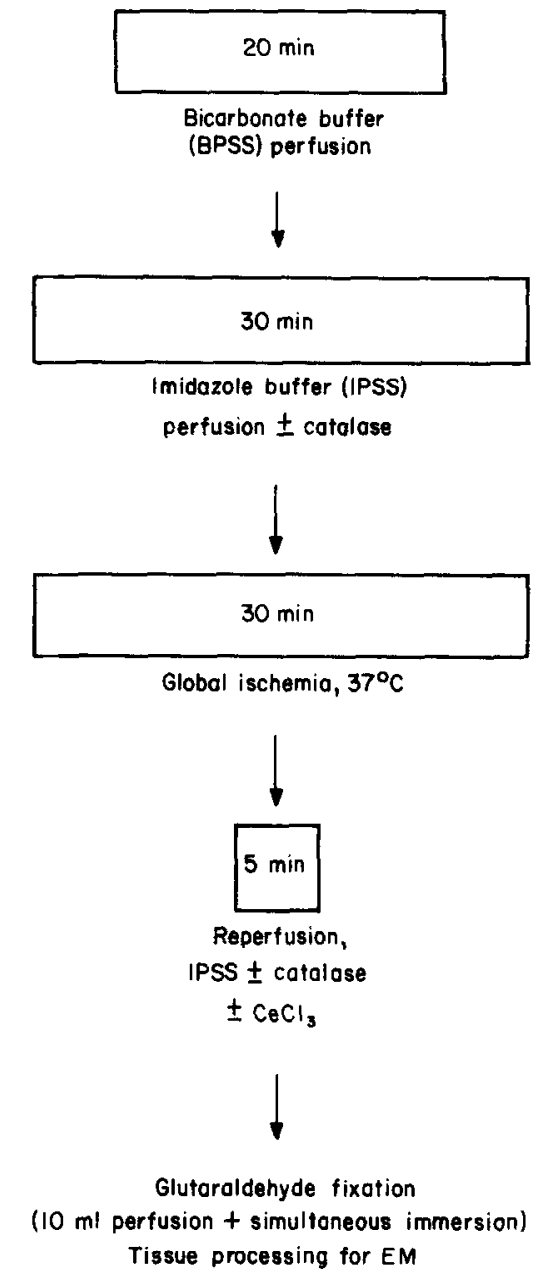

FIGURE 1. Schematic diagram of experimental protocol, from perfusion to fixation.

ted based on the results of contractile studies in nonischemic hearts which revealed that, compared with several other buffers (e.g. $\mathcal{N}$-2hydroxyethyl piperazine $\mathcal{N}$-2-ethanesulfonic acid; Tris[hydroxymethyl] aminomethane), it caused the least alteration of contractile function and coronary flow upon switching from BPSS, and it was chemically compatible with $\mathrm{CeCl}_{3}$. The $\mathrm{pH}$ of the IPSS was adjusted to 7.4 with $\mathrm{HCl}$, and the solution was bubbled with pure $\mathrm{O}_{2}$. Perfusion pressure, which rose slightly upon the switch from BPSS to IPSS (see Results), was readjusted to $75 \mathrm{~mm} \mathrm{Hg}$ by reducing coronary flow with the perfusion pump. 


\section{Ischemia studies}

Equilibration continued for another $30 \mathrm{~min}$ with IPSS perfusion, at which time the perfusion pump was stopped to cause $30 \mathrm{~min}$ of complete, normothermic global ischemia. Five hearts were studied in this manner.

Since the anticipated histochemical product was due to $\mathrm{H}_{2} \mathrm{O}_{2}$, for five hearts we added 300 $\mathrm{U} / \mathrm{ml}$ of catalase (thymol-free, from bovine liver; Sigma) to the IPSS that was perfused before ischemia. The hypothesis was that catalase would metabolize $\mathrm{H}_{2} \mathrm{O}_{2}$ and thereby prevent or at least significantly reduce the ability of $\mathrm{H}_{2} \mathrm{O}_{2}$ to react with cerium.

Another group of hearts was perfused before ischemia with IPSS to which we added bovine serum albumin $(0.027 \mathrm{mg} / \mathrm{ml}$; weight equal to that used in catalase experiments; Fraction V, Sigma; $n=5$ ). Perfusate gas tension was maintained as described below for catalase.

We studied another group of ischemic hearts $(n=5)$ to which cerium was not administered.

When either catalase or albumin was used, the perfusate was first $\mathrm{pH}$-adjusted and equilibrated with $\mathrm{O}_{2}$ by direct bubbling through fritted glass for at least $30 \mathrm{~min}$. Direct gassing was stopped, protein was added with continual stirring, and gas tension was maintained by placing a tight-fitting inverted funnel and plastic wrap over the container, then passing $\mathrm{O}_{2}$ through the funnel stem. This prevented frothing and potential inactivation or loss of the added protein. Solid $\mathrm{CeCl}_{3}$ was added slowly to the oxygenated proteincontaining perfusate with continual stirring immediately before use.

\section{Nonischemic controls}

Two other groups of hearts ( $n=5$ each) were nonischemic controls that were perfused for a time equal to that of the ischemia experiments. One of these had catalase in the perfusate, the other did not. We have perfused nonischemic hearts for up to $1.5 \mathrm{~h}$ with the IPSS, and have noted no significant functional alteration different from that normally encountered with prolonged perfusion with bicarbonate buffer. In addition, pilot studies showed that IPSS had no unique effect on functional recovery following global ischemia, compared with the results obtained with bicarbonate-buffered perfusate.

\section{Timing of cerium administration}

At the end of ischemia (or after $30 \mathrm{~min}$ IPSS perfusion in controls) most hearts were reperfused for $5 \mathrm{~min}$ with oxygenated IPSS containing $1 \mathrm{~mm} \mathrm{CeCl}{ }_{3}$. Thus cerium administration occurred at a time when oxidant production was expected to be great. When catalase or albumin was added to the pre-ischemic IPSS they were included in the reperfusate at the same concentration. Cerium chloride perfusion was limited to $5 \mathrm{~min}$ because cerium caused negative inotropy and, if perfusion was continued beyond that time, ventricular contracture occurred (see Results).

\section{Tissue fixation and preparation}

Hearts were fixed by retrograde aortic perfusion with approximately $10 \mathrm{ml}$ of buffered glutaraldehyde $(4 \%$ in $0.1 \mathrm{~m} \mathrm{Na}$ cacodylate, $\mathrm{pH} 7.5$, plus $5 \% \mathrm{w} / \mathrm{v}$ sucrose) to remove residual intravascular perfusate and begin intravascular fixation. They were immersed simultaneously in approximately the same volume of the same fixative to begin homogeneous fixation of the cpicardium. Hearts were then removed from the cannula and samples of left ventricular papillary muscles and the free wall were removed with a scalpel. They were quickly minced into pieces of approximately $1 \mathrm{~mm}^{3}$ or less, and fixed at room temperature with gentle rotation for $90 \mathrm{~min}$. Samples were rinsed three times in sucrosecacodylate buffer $(5 \%$ sucrose, $0.1 \mathrm{~m}$ sodium cacodylate, $\mathrm{pH}$ 6) to remove precipitate formed artifactually and nonspecifically during incubation (Briggs et al., 1975). Samples were then rinsed twice with sucrosecacodylate buffer at $\mathrm{pH} 7.5$, and stored overnight at $4^{\circ} \mathrm{C}$ in this solution. Subsequent processing involved $2 \% \mathrm{OsO}_{4}$ postfixation at $4^{\circ} \mathrm{C}$, then room temperature ethanol dehydration, propylene oxide infiltration, and embedding in EMBED $812^{\circledR}$ (Electron Microscopy Sciences, Ft. Washington, PA).

Gold or silver sections from the blocks (see sampling details below) were mounted on copper grids. Most were counterstained with uranyl acetate and lead citrate according to 
standard protocols. Sections were examined and photographed in a JEOL JEM $1200 \mathrm{EX}$ or Zeiss EM10-A transmission electron microscope, with a typical accelerating voltage of 60 $\mathrm{keV}$. Most exposures were taken at $15000 \times$ to achieve some consistency for later analysis of prints. Others were taken at 2000 to $3000 \times$ to show larger areas of myocardium and endothelial cells for better assessment of the homogeneity of treatment-related effects.

\section{Microbeam analysis}

Thin sections (some counterstained, others not) from hearts in all groups were carboncoated and subjected to electron microbeam (X-ray) analysis in a JEOL 2000FX electron microscope equipped with a Tracor TN5500 Series II X-ray analyzer. This method was used to assess ion content at sites of obvious precipitation on the luminal face of the endothelium (see Results), as well as at other sites where there was less or no precipitate evident from visual inspection. Accelerating voltages of approximately $200 \mathrm{keV}$, and acquisition times of 500 to $2000 \mathrm{~s}$, were found to optimize signal acquisition yet minimize sample destruction or movement. At the nominal microscope magnification we used, $15000 \times$, the probe beam focused on an area having an approximate diameter of $200 \mathrm{~nm}$.

\section{Sampling, assessment of micrographs, and data analysis}

Eight to 10 blocks were prepared from each heart. Two to five grids prepared from each block were randomly selected, examined, and photographed. Four to five photomicrographs were taken from each grid. The person responsible for electron microscopy and photography (K.B.) sequentially numbered prints of all negatives and did not participate in their subsequent evaluation.

Prints were evaluated by the remaining authors, and by other persons familiar with cardiac ultrastructure, using a semiquantitative score to assess the precipitate. Initial inspection of prints from both counterstained and unstained sections readily showed that the majority of obvious precipitation was at the luminal face of the endothelium, so further assessment emphasized that site. Scores ("visual scores") were assigned as follows: $0=$ no precipitate, clean and/or normal; $1=$ minor (patchy or diffuse) precipitate, mostly clean or normal; $2=$ moderate (patchy or diffuse) precipitate; $3=$ heavy, diffuse or localized precipitate, few normal areas; $4=$ heavy and widespread or confluent precipitate, no clean areas. The grading scale was explained to each investigator, and a micrograph from each grade (not used for computation of final data) was shown for orientation, before all other micrographs were graded in blinded fashion. Grades from each evaluator, and for each micrograph, were averaged.

For corroborative quantitative data we used computer-based morphometry to analyze 53 electron micrographs selected randomly from three Ce-treated groups: ischemia-reperfusion; ischemia-reperfusion plus catalase; and nonischemic controls without catalase. Four micrographs of ischemicreperfused hearts that were not perfused with $\mathrm{CeCl}_{3}$ were also analyzed. Images were digitized from contact prints (all having a magnification of approximately $15000 \times$ ) using a video camera and a Zeiss SEM-IPS ${ }^{\circledR}$ Image Analyzer. Images were shade-corrected and segmented based on gray level to separate the material of interest (the precipitate) from the background. Once adjusted for the original image magnification, the analyzer calculated the length of the luminal face of the endothelium (in $\mu \mathrm{m}$ ), the area occupied by precipitate (in $\mu \mathrm{m}^{2}$ ), and the area/length ratio. This ratio estimates the hypothetical depth of precipitate (in $\mu \mathrm{m}$ ) if it were distributed over the luminal face in uniform thickness. The person who performed the image analysis was unaware of the groups to which the micrographs belonged.

Visual and computer-derived scores for each micrograph in each group were averaged (and reported as \pm 1 s.E.M.), tabulated, and subjected to analysis of variance. A regression coefficient was calculated to assess for a relationship between data obtained with visual vs. computer-derived analysis. For one analysis, computer-derived scores were used as the independent variable, visual scores as the dependent variable. The variables were reversed for the second analysis, which gave statistically identical results. We used Scheffe's $F$-test, which accounts for multiple-group com- 
parisons, to compare data between the nonischemic and ischemic-reperfused groups. Unless noted otherwise all statistics were obtained using this test.

Treatment-related effects on overall myocyte or endothelial morphology were not analyzed quantitatively.

\section{Results \\ Contractile effects of cerium perfusion}

Figure 2 shows the effects on a nonischemic heart of switching from BPSS to IPSS, and subsequent perfusion with $\mathrm{CeCl}_{3}$. The buffer switch quickly caused modest bradycardia, a slight fall of peak left ventricular pressure development, and a slight rise of perfusion pressure. Once perfusion pressure was lowered manually by reducing flow, contractile parameters remained constant throughout the duration of IPSS perfusion. Upon perfusion with $1 \mathrm{~mm} \mathrm{CeCl}_{3}$ there was a prompt negative inotropic response and a fall of perfusion pressure. The surface electrogram of the heart (measured in several separate experiments; data not shown) persisted, indicative of excitation-contraction uncoupling. With continued $\mathrm{CeCl}_{3}$ perfusion left ventricular enddiastolic pressure rose. If coronary (perfusion pump) flow was left alone, perfusion pressure rose also. As noted above, hearts were fixed after only $5 \mathrm{~min}$ of $\mathrm{CeCl}_{3}$ perfusion, well before significant rises of end-diastolic pressure and frank ventricular contracture occurred.

\section{Electron microscopic results}

The general morphology of sections of ischemic-reperfused hearts showed changes typical of ischemic damage, but we did not conduct a formal morphometric evaluation of this. Such changes included clarification of the endothelium and/or variable amounts of separation from the myocytes beneath. Varying degrees of sarcoplasmic clarification, myofibrillar contraction and occasional contracture, and swelling of the sarcotubular network and mitochondria, were observed. Formed elements of the blood were not found in any of
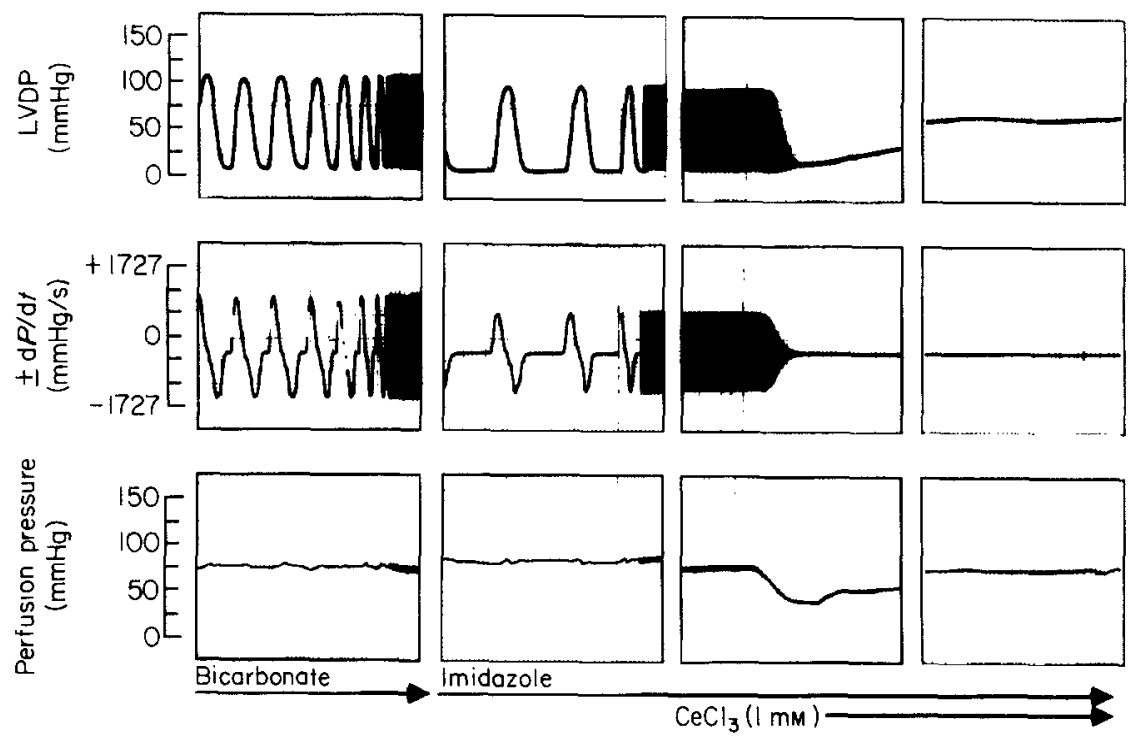

FIGURE 2. Effects of switching from bicarbonate-buffered PSS to one containing imidazole (IPSS), and administration of $\mathrm{CeCl}_{3}$. The panels show (top to bottom) left ventricular developed pressure (LVDP), its electronically derived first derivative $(\mathrm{dP} / \mathrm{dt})$, and perfusion pressure during constant-flow perfusion. Switching to IPSS (second vertical panels from left) caused a slight fall of LVDP and $\mathrm{d} P / \mathrm{d} t$, and a rise of perfusion pressure that was corrected by slight lowering of the perfusion pump rate. Administering $\mathrm{CeCl}_{3}$ caused negative inotropy, excitation-contraction uncoupling (electrogram data not shown) and, over $15 \mathrm{~min}$ (last vertical panels on right), contracture. Recorder speed was 25 $\mathrm{mm} / \mathrm{min}$ except for the left-hand portions of the first and second vertical panels, which was $25 \mathrm{~mm} / \mathrm{s}$. 


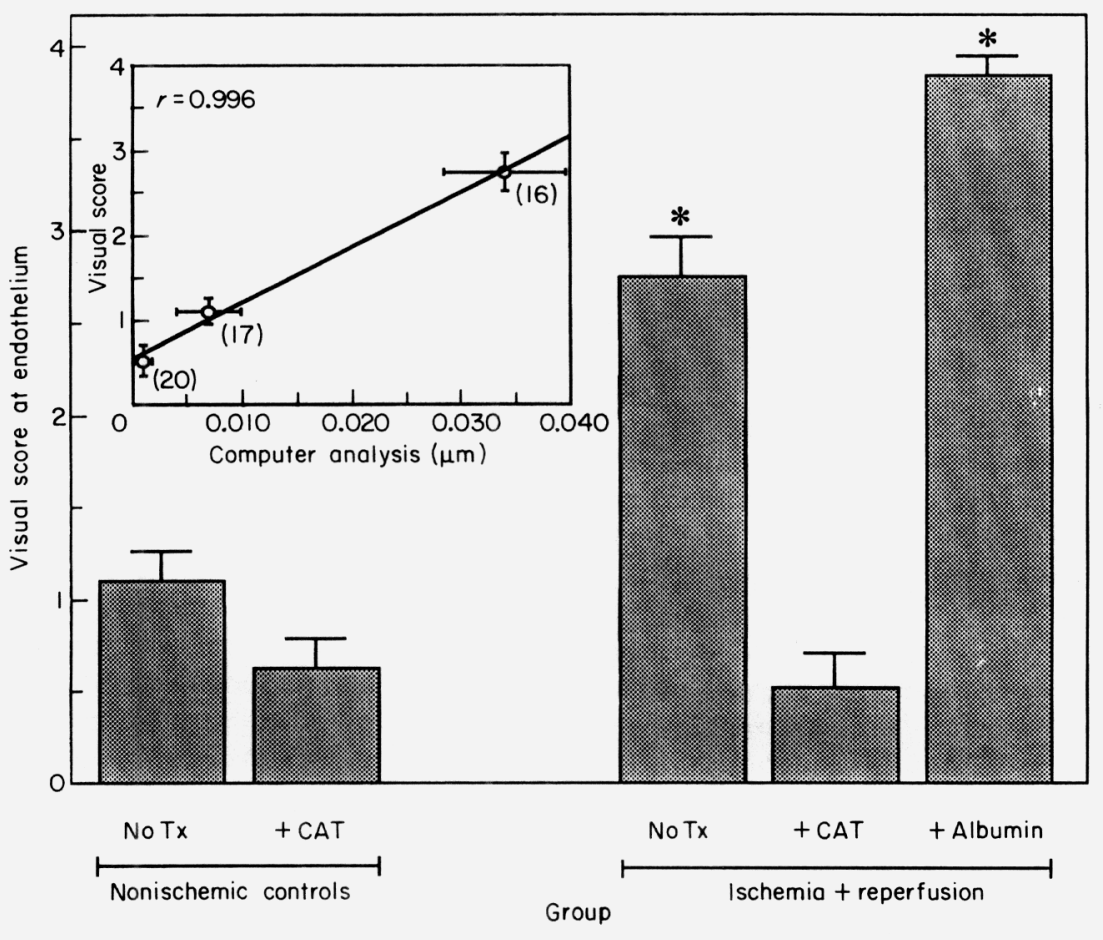

FIGURE 3. Graph summarizing mean visual scores ( \pm 1 S.E.M.) for endothelial cerium precipitate in nonischemic and ischemic-reperfused hearts. Asterisk indicates significant difference $(P \ll 0.05)$ from value for nonischemic control. Inset: Computerized morphometric assessment of electron micrographs from three $\mathrm{CeCl}_{3}$-treated groups [ischemia + reperfusion with catalase (CAT; 20 micrographs, indicated in parentheses) or without catalase pretreatment (No Tx; 16 micrographs); nonischemic controls (17 micrographs)] correlated significantly $(r=0.996$; $P<0.0001$ ) with visual scores for the same photos. Abscissa values are in $\mu \mathrm{m}$, the hypothetical depth of the precipitate if it were uniformly distributed over the luminal surface of the endothelium in the field (see text). Values are arithmetic means \pm 1 S.E.M.

the microscope fields, whether from nonischemic or ischemic-reperfused hearts.

When data using the two methods for grading endothelial-luminal face precipitate were compared, we obtained a correlation coefficient of $0.996 \quad(P<0.001$; Figure 3 inset $)$, indicating excellent agreement between methods. We found statistically significant differences $(P<0.001$ based on analysis of variance of all groups' data; Figure 3 ) in the amount of endothelial precipitation in the various groups, regardless of the grading method used. The results were very consistent for each grid, block, heart, and evaluator, and did not differ statistically when data from counterstained or unstained sections were compared.

Figure 4 shows three histochemical features seen in hearts reperfused with $\mathrm{CeCl}_{3}$ but with- out catalase pretreatment. Routinely there was dense and abundant precipitation (group mean visual score: $2.75 \pm 0.22$; computer: $0.0342 \pm 0.056 \mu \mathrm{m}$ ) almost exclusively at the luminal face of endothelial cells. Occasionally precipitate of comparable density was found in what appeared to be pinocytotic vesicles in the endothelium, and in what appeared to be tight junctions between endothelial cells. When the endothelial cell was closely apposed to the sarcolemma, we could not detect material of equivalent density or appearance at other sites, whether in high or low power fields or in sections that were or were not counterstained.

Electron microbeam analysis of precipitate at the luminal endothelial sites (Fig. 5) revealed three peaks at $4.8,5.2$, and $5.6 \mathrm{keV}$. These correspond to Ge (Bruijn et al., 1980). 


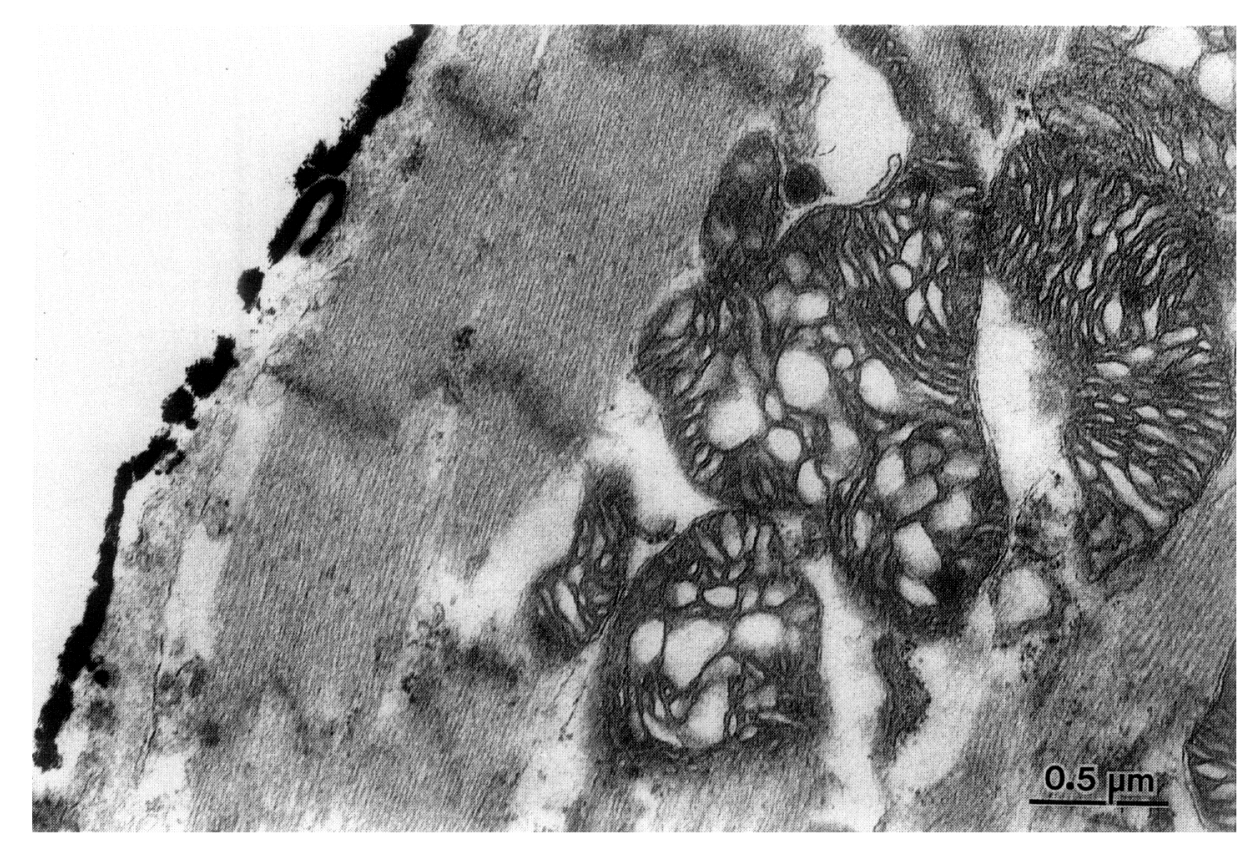

FIGURE 4. Localization of precipitate in $\mathrm{CeCl}_{3}$-treated ischemic-reperfused hearts without catalase or albumin pretreatment (lead citrate and uranyl acetate counterstained). Precipitate was observed mainly on the luminal face of endothelial cells. Expected consequences of ischemic damage on myocyte morphology (e.g. mitochondrial swelling, myofibrillar derangements, sarcoplasmic clarification) are apparent. The mean visual endothelial (luminal face) precipitate score for this group was $2.75 \pm 0.22$ ( $P \ll 0.05$ vs. nonischemic control group; Scheffe's $F$-test). For this and all other electron micrographs, the scale bar indicates true image magnification.

Spectral peaks for lead and uranium appeared with counterstained sections. When there was a visually distinct separation between the endothelium and the adjacent myocyte (Fig. 5 ), we occasionally observed additional electron-dense material over or on the abluminal face of the endothelium, as well as at the sarcolemmal glycocalyx. When present it was always visually smaller, more diffuse, and less dense than what was observed at the luminal endothelial face. These characteristics may explain why, when the X-ray beam was moved over these sites, Ce peaks could not be detected. Peaks for lead and uranium persisted. Thus, we cannot state definitively whether this material contained cerium.

The visual score for albumin-treated hearts (Fig. 6) was $3.84 \pm 0.11$ (computerized morphometry was not used for this group). This value was not significantly different $(P>$ $0.05)$ from values for the ischemic-reperfused hearts that received no catalase. Microbeam data were comparable for hearts in these two groups.

Mean precipitate scores in catalasetreated, ischemic-reperfused hearts (visual: $0.52 \pm 0.19$; computer: $0.0014 \pm 0.0008 \mu \mathrm{m}$; Fig. 7) were significantly lower $(P<0.0001)$ than scores for the other ischemic-reperfused, cerium-treated groups. We found no evidence of additional fine granular material in the interstitial spaces, as seen in sections of hearts not treated with catalase.

The morphology of nonischemic control, cerium-treated hearts (Fig. 8) appeared characteristically normal and showed good fixation. Their ultrastructure did not differ from that of nonischemic controls that were not perfused with $\mathrm{CeCl}_{3}$, suggesting that $\mathrm{CeCl}_{3}$ caused no observable morphologic effects of its own during brief treatment. The luminal-endothelial precipitate scores for this group (visual: $1.10 \pm 0.16$; computer: $0.0067 \pm 0.0029 \mu \mathrm{m} ;$ Fig. 8) were significantly 

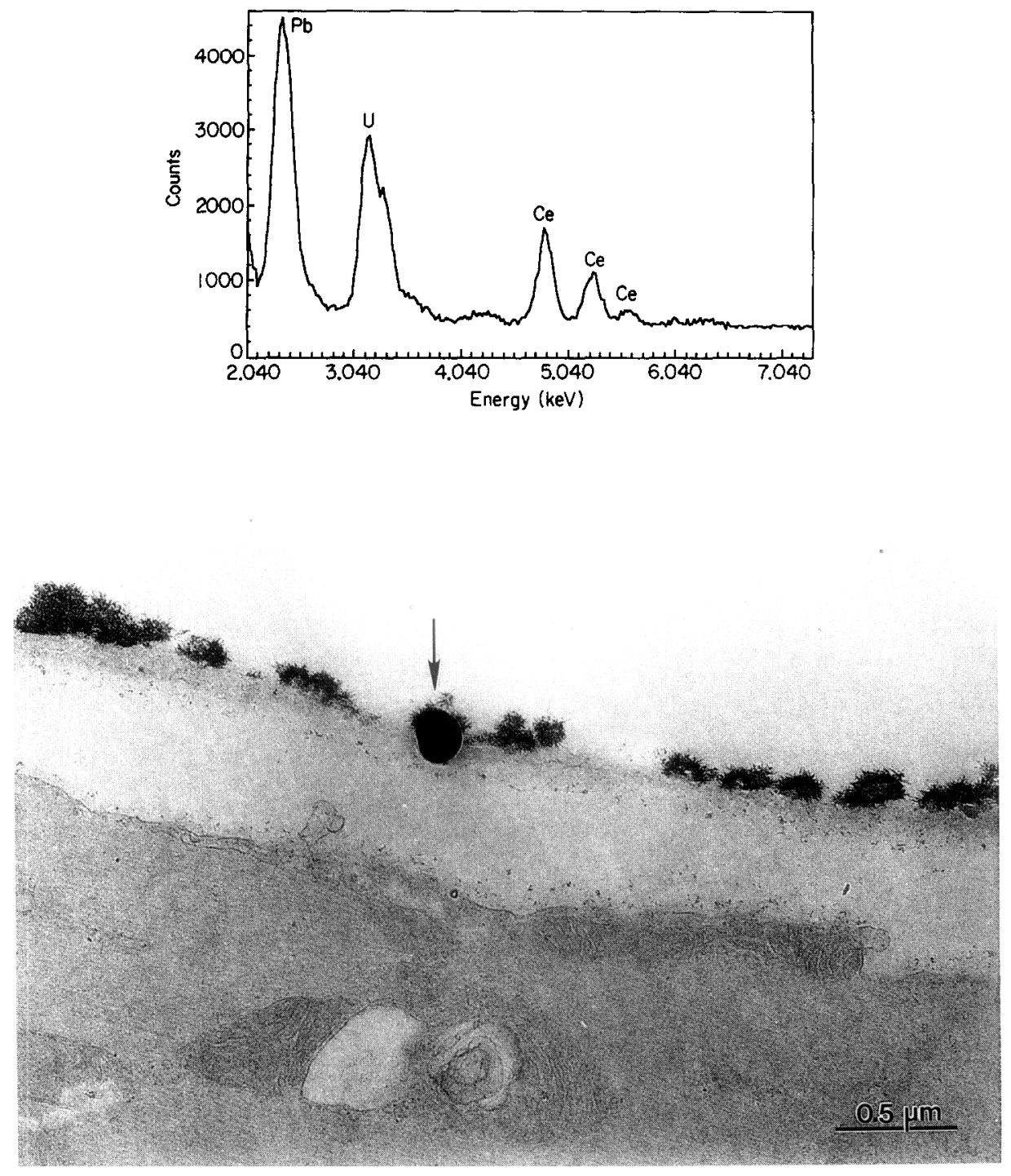

FIGURE 5. Electron micrograph from ischemic-reperfused $\mathrm{CeCl}_{3}$-treated heart (no catalase or albumin; from same group as shown in Fig. 4), and microbeam spectrum obtained on luminal face of endothelium (shown below). The sampling site for microbeam analysis is the dark spot marked with an arrow. The nominal diameter of this spot, $200 \mathrm{~nm}$, and the acquisition time ( $784 \mathrm{~s}$ ), are comparable to those used to evaluate other sites. Accelerating voltage of $200 \mathrm{keV}$ and use of carbon-coated grid accounts for the decreased contrast. Note the fine electron-dense material on the abluminal face of the endothelium, and over the sarcolemmal basement membrane. It was less dense and more diffuse than that seen on the luminal endothelial face. With the maximum spectral acquisition times we could use without destroying the specimen or contaminating the microscope, we were unable to detect cerium (Ce) at these loci, or at other sites (e.g. inside myocytes) where no precipitate was apparent. Other abbreviations on spectrum: $\mathrm{Pb}$, lead; $\mathrm{U}$, uranium (used as counterstains).

less than those obtained in the nontreated and albumin-treated ischemic-reperfused groups $(P<0.0001)$. This score was not significantly different $(0.50>P>0.25)$ from that for the catalase-treated reperfused hearts. Examination of the nonischemic controls also revealed some fine and dispersed electron-dense material in the interstitial space, sometimes restricted to the basement membrane on the abluminal side of the endothelium and over the sarcolemma (Fig. 8, inset), suggesting that some cerium-peroxide reaction occurred. 


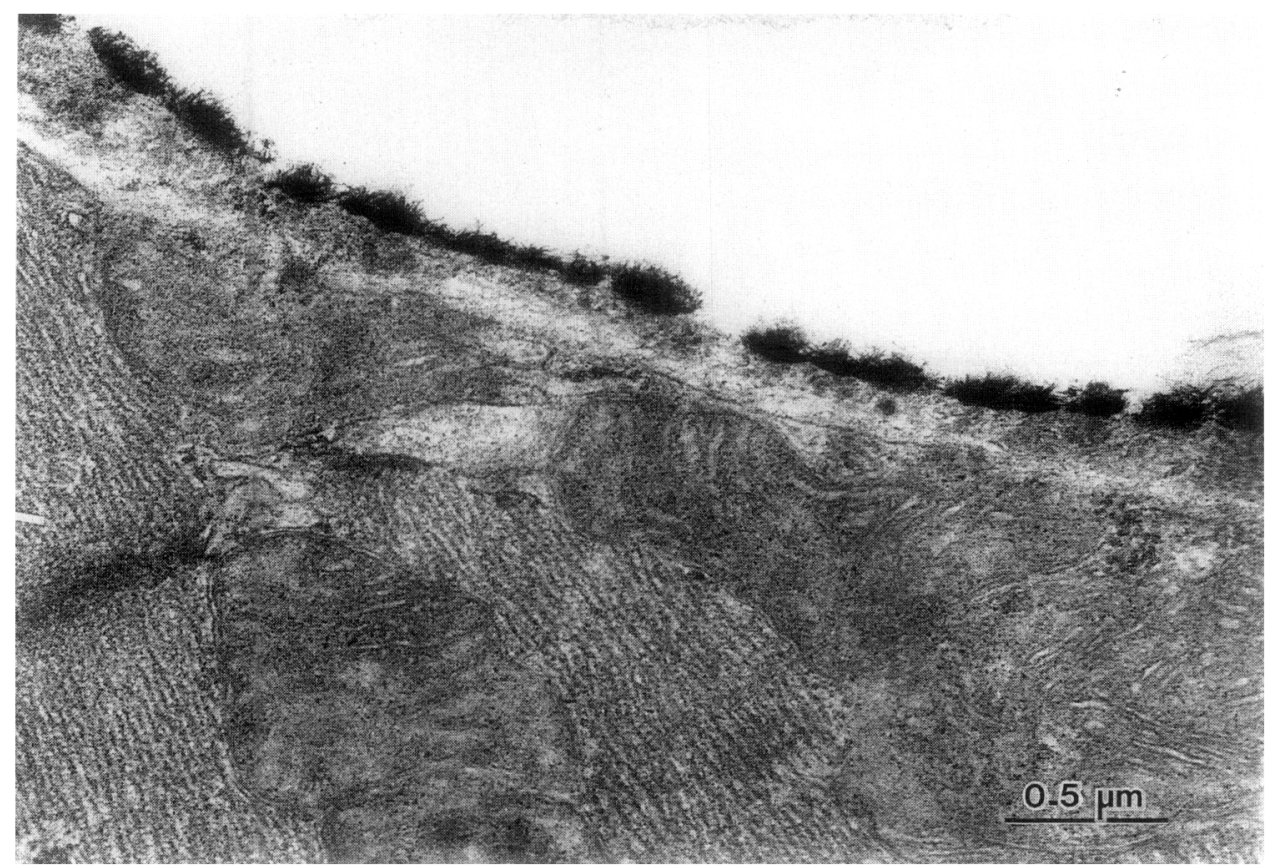

FIGURE 6. Electron micrograph of heart pre-treated with albumin (weight per ml equal to that of catalase) then reperfused with $\mathrm{CeCl}_{3}$. Albumin failed to reduce precipitate intensity or location compared with results obtained with catalase. The mean luminal endothelial precipitate score for this group was $3.84 \pm 0.11(P>0.05$ vs. ischemic control; $P \ll 0.05$ vs. nonischemic controls; Scheffe's $F$-test).

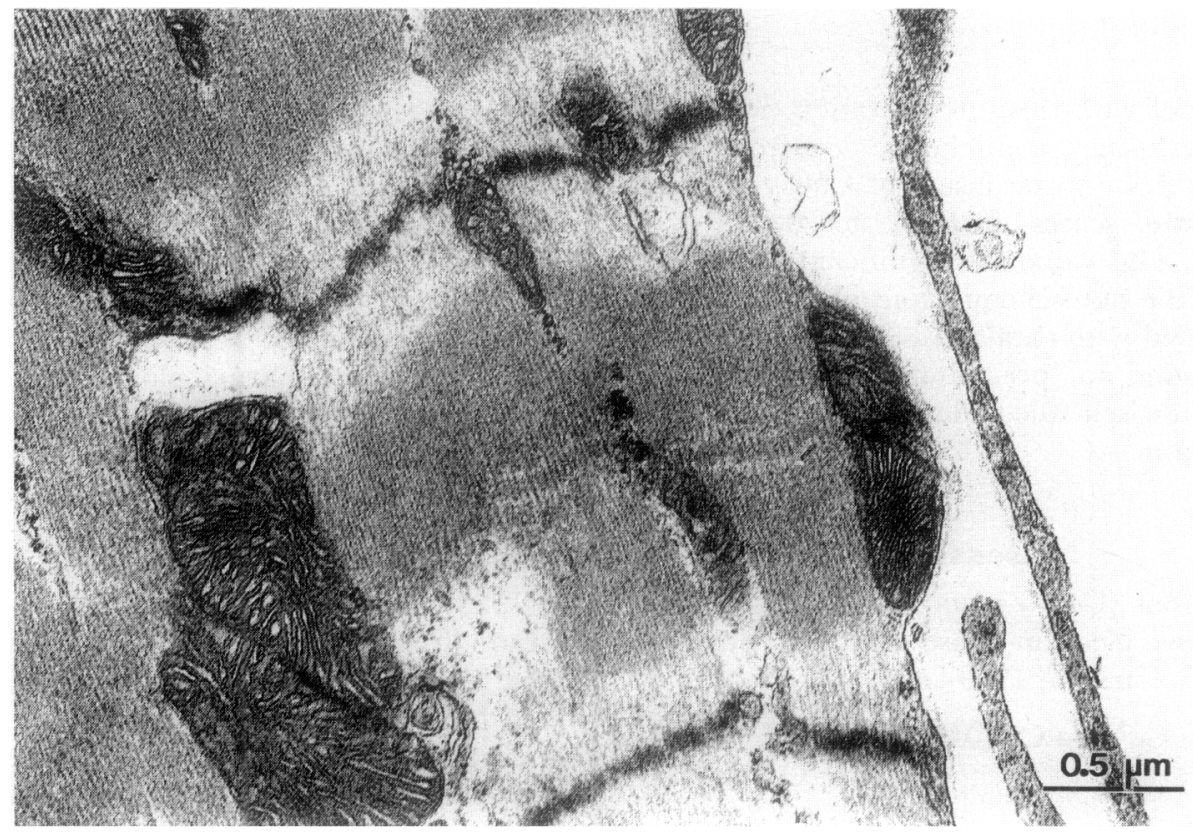

FIGURE 7. Pre-treating hearts with catalase $(300 \mathrm{U} / \mathrm{ml})$ significantly reduced and in some cases eliminated precipitate at the luminal face of the endothelium. It completely eliminated fine densities seen on the abluminal face and in the interstitial space [cf. Figs 5 and 8 (inset)]. The visual score in this micrograph is zero; the mean score for all micrographs in this group was $0.52 \pm 0.19(P>0.05 \mathrm{vs}$, nonischemic control group; $P \ll 0.05$ vs. ischemic controls; Scheffe's $F$-test). 


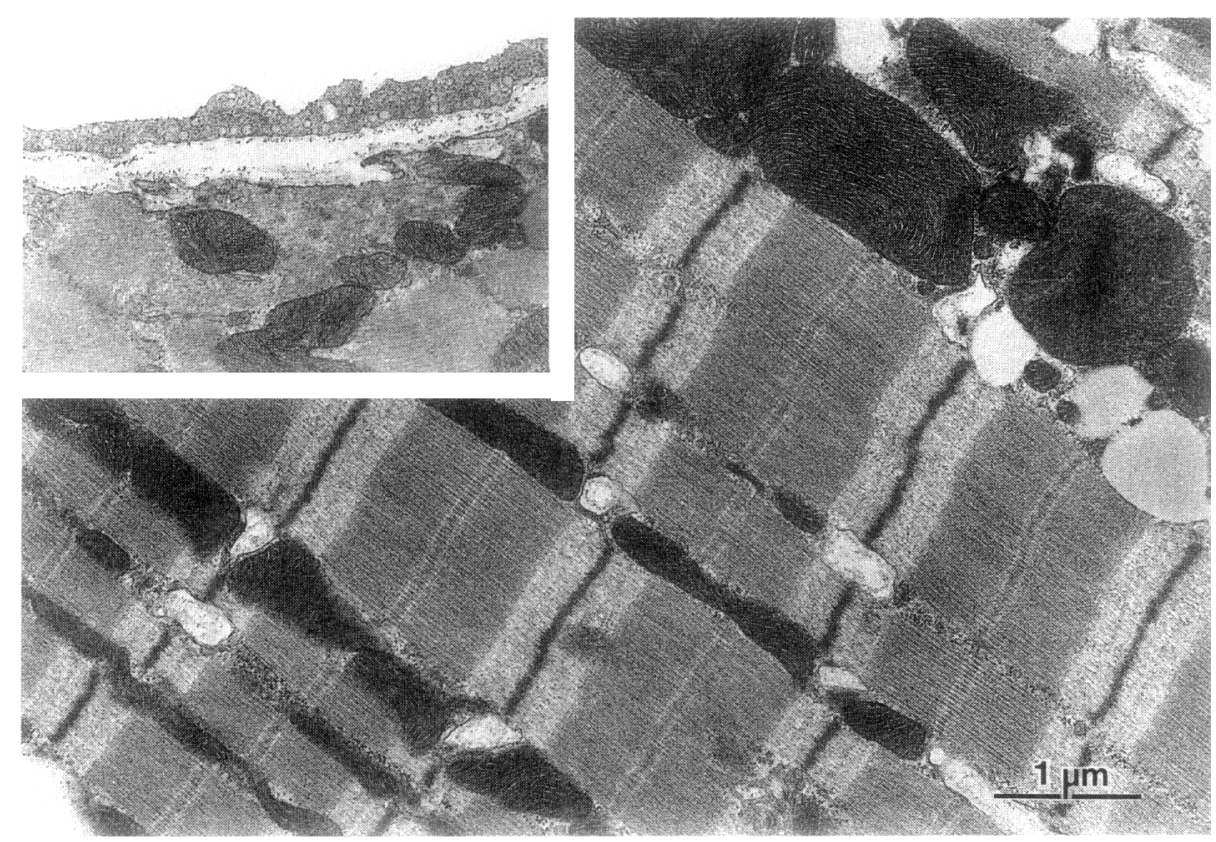

FIGURE 8. Myocytes and endothelium (inset) from nonischemic controls perfused with $\mathrm{CeCl}_{3}$, but without catalase pretreatment. The morphology is typical of well-fixed, nonischemic myocardial cells. The inset (same magnification as large micrograph) shows small amounts of fine diffuse electron-dense material on both the luminal and abluminal sides of the endothelium, as well as on the basement membrane over the sarcolemma (cf. Fig. 5). The mean precipitate score, assessed visually at the luminal face of the endothelium, was $1.10 \pm 0.16$.

Consistent with this interpretation, we found that perfusing nonischemic controls with catalase prior to perfusion of $\mathrm{CeCl}_{3}$ reduced precipitate scores further, to $0.63 \pm 0.15$ (Fig. 3). This value was significantly less than that of the nonischemic controls which were not treated with catalase.

We found no "precipitation" in hearts that were made ischemic and then reperfused without cerium.

\section{Discussion}

Cerous ions $\left(\mathrm{Ce}^{3+}\right)$ react with $\mathrm{H}_{2} \mathrm{O}_{2}$ to form one or two electron-dense products (Briggs et al., 1975; Kuroda, 1989):

$$
\begin{array}{r}
\mathrm{H}_{2} \mathrm{O}_{2}+\mathrm{Ce}^{3+} \rightarrow \mathrm{Cc}(\mathrm{OH})_{2} \mathrm{OOH} \text { or } \\
\mathrm{Ce}(\mathrm{OH})_{3} \mathrm{OOH}
\end{array}
$$

Through this reaction $\mathrm{CeCl}_{3}$ has been used as a capture agent for the ultrastructural cytochemical demonstration or localization of $\mathrm{H}_{2} \mathrm{O}_{2}$ produced by such cells or tissues as neutrophils (Briggs et al., 1975; Butterick et al., 1983; Vissers et al., 1985), macrophages (Wozencraft et al., 1985; Kuroda, 1986), thyroid (Labato and Briggs (1985), liver (Veenius and Wendelaar Bonga, 1979), lung (Warren et $a l .$, 1989) and heart (Christie and Stoward, 1982; Vandeplassche et al., 1989). These studies often use pharmacologic concentrations of exogenous substrates or inhibitors to stimulate or inhibit peroxide production, and rely on incubation of the biologic material in cerium-containing media.

Of the myocardial studies, Vandeplassche $e t$ al. (1989) incubated fixed, sectioned myocardium from regionally ischemic hearts in media containing $\mathrm{CeCl}_{3}$, with or without added NADH. Although they did not assess the effects of catalase on the cytochemical reaction, their data suggest that even after a modest ischemic insult mitochondrial NADH oxidase activity can produce $\mathrm{H}_{2} \mathrm{O}_{2}$. Christie and Stoward (1982) incubated small pieces of myocardium in media containing $\mathrm{CeCl}_{3}$ and a 
variety of metabolic substrates and inhibitors, and demonstrated a putative $\mathrm{H}_{2} \mathrm{O}_{2}$-cerium reaction product thought to arise from an enzyme with the properties of diamine oxidase. Although they used unfixed tissue, their study was not done under conditions that preserve or allow measurement of cell function.

Our study differed methodologically in several ways from those cited above. We administered cerium by perfusion to intact isolated hearts that, up to the time of histochemical intervention and fixation, had some measureable level of function. The stimulus for increased $\mathrm{H}_{2} \mathrm{O}_{2}$ formation, reperfusion and concomitant reoxygenation following ischemia, was a pathophysiologically relevant one, not the administration of an exogenous chemical. Cerium administration was timed to coincide with reperfusion. Importantly, the method allowed us to show that a component of $\mathrm{H}_{2} \mathrm{O}_{2}$ which is produced (regardless of its sites or biochemical pathways of origin) gains access to the vascular compartment, which might be expected from data showing that perfused catalase can alter functional and biochemical consequences of ischemic or hypoxic myocardial damage (Myers et al., 1985,1986 ).

Several questions arise from this study. (1) Was the reaction product we observed both cerium- and $\mathrm{H}_{2} \mathrm{O}_{2}$-dependent, and (2) did its amount reflect the amount of $\mathrm{H}_{2} \mathrm{O}_{2}$ produced? (3) If $\mathrm{H}_{2} \mathrm{O}_{2}$ was involved, what are its sources? (4) What factors may have influenced precipitate localization? Finally (5), what are the biologic implications of the findings?

We cannot prove whether the precipitate arose from a direct reaction between $\mathrm{Ce}^{3+}$ and $\mathrm{H}_{2} \mathrm{O}_{2}$, but it is reasonable to postulate that it was, at least, both cerium- and peroxide-dependent. Electron microbeam data showed that the dense endothelial deposits we observed in hearts treated with $\mathrm{CeCl}_{3}$ indeed contained cerium. No comparable deposits were observed in hearts not perfused with $\mathrm{CeCl}_{3}$, but otherwise treated similarly. Thus, the densities were ceriumdependent.

We did not measure $\mathrm{H}_{2} \mathrm{O}_{2}$ directly, as with a biochemical technique, so we cannot prove that peroxide was formed. However the likelihood that $\mathrm{H}_{2} \mathrm{O}_{2}$ was produced by some cell(s) within the heart is supported by the histochemical data plus other direct and indirect evidence (Christie and Stoward, 1982; Shlafer et al., 1982a, b; Myers et al., 1985, 1986).

The significantly greater amount of precipitate seen in ischemic-reperfused, ceriumtreated hearts, indicates that ischemia and/or reperfusion increased the availability of a constituent in the histochemical reaction. Perfusate $\mathrm{CeCl}_{3}$ concentration was constant in all experiments, and there is no reason to assume that any of the treatments used or interventions imposed would increase cerium reactivity. This suggests that more $\mathrm{H}_{2} \mathrm{O}_{2}$ was available, contributing to the greater amount of precipitate. The ability of submicromolar concentrations of catalase to reduce the amount of reaction product significantly also supports the involvement of $\mathrm{H}_{2} \mathrm{O}_{2}$. It is conceivable that reduced precipitation in the presence of catalase was due to nonspecific adsorption of cerium to the protein. However the wellknown ability of catalase to quickly and effectively degrade $\mathrm{H}_{2} \mathrm{O}_{2}$ enzymatically, plus the inability of albumin to inhibit precipitate formation, argue against this alternative explanation. Catalase administration did not yield mean scores of zero at the endothelium, whether assessed in nonischemic hearts (mean score 0.62) or ischemic hearts (mean score 0.52 ). One interpretation of this is that a small component of the precipitate was either nonspecific, or represented precipitation between $\mathrm{Ce}^{3+}$ and phosphate, as discussed below.

The reaction product we measured probably underestimates the amount of $\mathrm{H}_{2} \mathrm{O}_{2}$ produced. Some of the $\mathrm{H}_{2} \mathrm{O}_{2}$ may have reacted with cellular constituents, or with $\mathrm{O}_{2}{ }^{-}$and $\mathrm{Fe}^{3+}$ to form $\mathrm{OH}$, before it could react with $\mathrm{CeCl}_{3}$. Another portion may have been degraded by endogenous catalase and glutathione peroxidase, whether in the myocyte or endothelium. Ischemia-induced partial loss or inactivation of myocyte glutathione peroxide, with the potential concomitant reduction in the cell's ability to degrade $\mathrm{H}_{2} \mathrm{O}_{2}$, has been reported (see Shlafer et al., 1987). Such diminished defenses may explain why we were able to detect any precipitate $\left(\mathrm{H}_{2} \mathrm{O}_{2}\right)$ at all. The underestimate also probably reflects restricted access of cerium to $\mathrm{H}_{2} \mathrm{O}_{2}$, given the apparently limited ability of perfused cerium to 
cross the sarcolemma. As discussed later, this may be especially true for myocyte-derived $\mathrm{H}_{2} \mathrm{O}_{2}$.

Cerous ions also form an electron-dense precipitate with phosphate. This is the basis for using $\mathrm{CeCl}_{3}$ in cytochemical studies of several enzymes that hydrolyze phosphatecontaining substrates (Robinson and Karnovsky, 1983a, b; Rechardt and Hervonen, 1985; Dort $e t$ al., 1987), including those found in the heart (Borgers et al., $1971 \mathrm{a}$, b; Schulze et al., 1986). Thus a portion of the precipitate in nonischemic hearts might involve phosphate liberated during normal cell metabolism; the greater amount of precipitate in ischemicreperfused hearts could reflect greater amounts of phosphate arising from cell damage, which in turn might be reduced by a protective intervention such as catalase. However the phosphate-liberating enzymes that have been studied with cerium are not inhibited by catalase, nor is there evidence that catalase inhibits the reaction between cerous ions and phosphate. This provides further support for the postulate that if the majority of precipitate we detected was not specifically one between $\mathrm{Ce}^{3+}$ and $\mathrm{H}_{2} \mathrm{O}_{2}$, it was at least $\mathrm{H}_{2} \mathrm{O}_{2}$-dependent. Studies of neutrophil 5'nucleotidase activity indicate that the amount of cerium phosphate reaction product is proportional to enzyme activity in a soluble in vitro system, suggesting that precipitate density seen in cytochemical preparations also reflects enzyme activity (Robinson and Karnovsky, 1983a). This relationship may also apply to the interaction between $\mathrm{Ce}^{3+}$ and $\mathrm{H}_{2} \mathrm{O}_{2}$. However a reaction between $\mathrm{Ce}^{3+}$ and phosphate, perhaps released through peroxide-independent processes, may account for the small amounts of precipitate seen in catalase-treated nonischemic or ischemic hearts.

It seems apparent from the current data that some $\mathrm{H}_{2} \mathrm{O}_{2}$ is present at the luminal face of the endothelium. The most difficult question to answer with the current data is from where the $\mathrm{H}_{2} \mathrm{O}_{2}$ arose. One possibility is that the endothelium is an important site of $\mathrm{H}_{2} \mathrm{O}_{2}$ generation in this model, based on the predominant loci of precipitate. Endothelial xanthine oxidase is not a likely $\mathrm{H}_{2} \mathrm{O}_{2}$ source (Jarasch et al., 1981, 1986), since the rabbit heart lacks xanthine oxidase activity (Grum et al., 1986, 1987; Downey et al., 1987) at levels that are likely to be (patho)physiologically relevant and at substrate concentrations near the enzyme's $\boldsymbol{K}_{\mathrm{m}}$ value (see Wajner and Harkness, 1989). Human myocardium is similar (Eddy et al., 1987; Grum et al., 1989). Moreover, we were unable to alter endothelial precipitation by pre-treating rabbit hearts with $1 \mathrm{~mm}$ allopurinol, a xanthine oxidase inhibitor, administered at times identical to those used here for catalase or albumin (unpub. obs.). Nevertheless the endothelial cell has several other biochemical pathways that could produce oxidants, including $\mathrm{H}_{2} \mathrm{O}_{2}$ (Hennig and Chow, 1988; Rubanyi, 1988; Halliwell, 1989), and they might account for the results. A technique involving cerium, plus the use of appropriate enzyme substrates and inhibitors method, may prove useful for evaluating them.

Another possibility is that the luminal face of the endothelium is merely the major site of reactivity between myocyte-derived $\mathrm{H}_{2} \mathrm{O}_{2}$ (e.g. from mitochondria Christie and Stoward, 1982; Shlafer et al., 1987a,b) and perfused cerium. However the amount of precipitate we found over the sarcolemma, abluminal endothelial face, and within the interstitial space, appeared small compared with that found on the luminal face of the endothelium. That they were not eliminated completely by catalase might be explained by a substantial inability of this large protein (MW 240000) to diffuse across the endothelium from its vascular delivery site and intercept myocytederived $\mathrm{H}_{2} \mathrm{O}_{2}$.

Regardless of the cellular source(s), a fraction of the $\mathrm{H}_{2} \mathrm{O}_{2}$ that is not metabolized or does not react with cell constituents first could diffuse into the extracellular space, which in blood-free systems lacks an $\mathrm{H}_{2} \mathrm{O}_{2}$ source. Our data suggest that some $\mathrm{H}_{2} \mathrm{O}_{2}$ does reach the extracellular spaces, including the vascular compartment. Flow upon reperfusion would increase the $\mathrm{H}_{2} \mathrm{O}_{2}$ concentration gradient towards the vascular lumen, where cerium is being delivered simultaneously. This should favor diffusion of $\mathrm{H}_{2} \mathrm{O}_{2}$. Although diffusionrelated factors may affect precipitate localization, it is difficult to envisage how they could negate the involvement of $\mathrm{H}_{2} \mathrm{O}_{2}$ in precipitate formation.

The endothelium does not appear to be a 
total permeability barrier to cerium diffusion. This is based on the presence of diffuse densities in the interstitial space, even though their amount was too low to detect cerium with $\mathrm{X}$-ray analysis. The prompt negative inotropic effect and concomitant excitation-contraction uncoupling upon perfusing $\mathrm{CeCl}_{3}$ through otherwise functional nonischemic hearts also suggests that cerium reaches, at least, the sarcolemma or its glycocalyx during the brief administration period used for the histochemical reaction. Such responses resemble thosc caused by $\mathrm{La}^{3+}$ (Sanborn and Langer, 1970; Mezon and Bailey 1995).

Despite contractile and electrophysiologic similarities between $\mathrm{La}^{3+}$ and $\mathrm{Ce}^{3+}$, and between their crystal ionic radii $\left(\mathrm{Ce}^{3+}=1.034\right.$ $\hat{\AA} ; \mathrm{La}^{3+}=1.061 \AA$ ), it appears that cerium's histochemical reactivity and localization are affected by factors other than, or in addition to, those affecting lanthanum. When cells with normal sarcolemmae (i.e. nonischemic cells) are exposed to ionic or colloidal lanthanum (Langer and Frank, 1972; Hoffstein et al., 1975; Burton et al., 1977), whether by incubation or perfusion, lanthanum dcposits arc intense but they are predominantly localized at the interstitial face (glycocalyx) of the sarcolemma. When $\mathrm{CeCl}_{3}$ was perfused under largely similar conditions, the electron-dense material was slight and not found preferentially at the sarcolemma. When $\mathrm{La}^{3+}$ is administered to ischemically-damaged hearts, the substance can then be detected intracellularly, owing to disruption of the glycocalyx and sarcolemma that allows greater diffusion. Often this is accompanied by lesser amounts appearing on extracellular membrane faces. Moreover, when myocytes exposed to $\mathrm{La}^{3+}$ are pre-treated with some protective intervention prior to an insult such as ischemia, intracellular deposition is reduced. However there is no simultaneous and nearly complete reduction of lanthanum deposition on membrane faces exposed to the extracellular milieu. Cerium chloride did not behave in these ways in the presence or absence of ischemia or of catalase treatment.

It is difficult to envisage a process by which ischemia and reperfusion would dramatically intensify an alleged nonspecific $\mathrm{Ce}^{3+}$ binding, especially preferentially at the luminal face of the endothelium, compared with what was seen in nonischemic controls. It is also difficult to envisage how catalase could significantly reduce such deposition, other than through its ability to degrade $\mathrm{H}_{2} \mathrm{O}_{2}$. Thus, if a portion of the precipitate merely reflects nonspecific binding of cerous ions to anionic sites on basement membranes (myocyte or endothelium), that portion is likely to be small compared with what occurred through the postulated $\mathrm{Ce}^{3+}-\mathrm{H}_{2} \mathrm{O}_{2}$ interaction.

Our data have several biologic implications for the postulate that $\mathrm{H}_{2} \mathrm{O}_{2}$ and other oxidants participate in damage to hearts during ischemia and/or reperfusion.

We have provided histochemical evidence to support a postulate that $\mathrm{H}_{2} \mathrm{O}_{2}$, regardless of its cellular origin(s), gains access to the extracellular space upon reperfusion after 30 min of normothermic ischemia. The data are also consistent with the hypothesis that the pool of $\mathrm{H}_{2} \mathrm{O}_{2}$ we detected is accessible to degradation by catalase administered by vascular perfusion. It is not possible, however, to state whether the $\mathrm{H}_{2} \mathrm{O}_{2}$ we detected was responsible for a component of injury incurred by hearts subjected to comparable ischemic conditions.

In summary, a cerium histochemistry technique applied to intact, buffer-perfused hearts, appears to have potential as a useful probe of $\mathrm{H}_{2} \mathrm{O}_{2}$ production and fates in this organ. It may be particularly useful when used with pharmacologic interventions thought to affect oxidant metabolism. The method may be applicable to the study of other bufferperfused organs as well.

\section{Acknowledgements}

We thank Dr John F. Mansfield, Materials Science and Engineering, College of Engineering, for assistance with the microbeam analysis and use of his facilities; and Dr Thomas G. Connelly, Department of Anatomy and Cell Biology, Medical School, for performing the computerized image analyses. This work was supported by grants from The National Institutes of Health (HL-29499 and HL-01930) and The American Lung Association. 


\section{References}

Borgers M, Schaper J, Schaper W (1971a) Localization of specific phosphatase activities in canine coronary blood vessels and heart muscle. J Histochem Cytochem 19: 526-539.

Borgers M, Schaper J, Schaper W (1971b) Adenosine-producing sites in the mammalian heart: a cytochemical study. J Mol Cell Cardiol 3: 287-296.

Briggs RT, Drath DB, Karnovsky MI, Karnovsky MJ (1975) Localization of NADH oxidase on the surface of human polymorphonuclear leukocytes by a new cytochemical method. J Cell Biol 67: 566-586.

Bruijn WC de, Schellens JPM, Buttenen JMH van, Meulen J van der (1980) X-ray microanalysis of colloidal-goldlabelled lysosomes in rat liver sinusoidal cells after incubation for acid phosphatase activity. Histochemistry 66: 137-148.

Burton KP, Hagler HK, Templeton GH, Willerson JT, Buja LM (1977) Lanthanum probe studies of cellular pathophysiology induced by hypoxia in isolated cardiac muscle. J Clin Invest 60: 1289-1302.

Butterick CJ, Baehner RL, Boxer LA, Jersild RA (1983) Vitamin E. A selective inhibitor of the NADPH oxidoreductase enzyme system in human granulocytes. Am J Pathol 112: 287-293.

Christie KN, Stoward PJ (1982) The cytochemical reactivity of cerium ions with cardiac muscle. J Histochem Cytochem 15: 656-672.

DoRT JB VAN, ZEELEN JPH, BRUiJn WC DE (1987) An improved procedure for the X-ray microanalysis of acid phosphatase activity in lysosomes. Histochemistry 87: 71-77.

Downey JM, Mrura T, Eddy LJ, Mellert T, Hearse DJ (1987) Xanthine oxidase is not a source of free radicals in the ischemia rabbit heart. J Mol Cell Cardiol 19: 1053-1060.

Eddy LJ, Stewart JR, Jones HP, Engerson TD, MaCord JM, Downey JM (1987) Free radical-producing enzyme, xanthine oxidase, is undetectable in human hearts. Am J Physiol 253 (Heart Circ Physiol 22): H709-H711.

Grum CM, Gallagher KP, Kirsh MM, Shlafer M (1989) Absence of detectable xanthine oxidase in human myocardium. J Mol Cell Cardiol 21: 263-267.

Grum CM, Ketar LH, Myers CL, Shlafer M (1987) Purine efflux patterns after cardiac ischemia: relevance to allopurinol cardioprotection. Am J Physiol 252 (Heart Circ Physiol 21): H368-H373.

Grum CM, Ragsdale RA, Ketai LH, Shlafer M (1986) Absence of xanthine oxidase or xanthine dehydrogenase in the rabbit myocardium. Biochem Biophys Res Commun 141: 1104-1 108.

Halliwell, B (1989) Superoxide anion, vascular endothelium, and reperfusion injury. Free Rad Res Commun 5: 315-318.

Hennig B, Chow CK (1988) Lipid peroxidation and endothelial cell injury: implications in atherosclerosis. Free Rad Biol Med 4: 99-106.

Hoffstein S, Gennaro DE, Fox AC, Hirsch J, Streuli F, Weissmann G (1975) Colloidal lanthanum as a marker for impaired membrane permeability in ischemic dog myocardium. Am J Pathol 79: 207-218.

Jarasch E-D, Bruder G, Heid HW (1986) Significance of xanthine oxidase in capillary endothelial cells. Acta Physiol Scand [Suppl] 5:8: $39-46$.

Jarasch E-D, Grund C, Bruder G, Heid HW, Keenan TW, Franke WW (198I) Localization of xanthine oxidase in mammary gland epithelium and capillary endothelium. Gell 25: 62-87.

KuRODA M (1986) Ultracytochemical localization of superoxide dismutase activity in rabbit alveolar macrophages: a comparative study using $\mathrm{KO}_{2}$ or xanthine-xanthine oxidase as an $\mathrm{O}_{2}^{-}$-generating system. Acta Histochem Cytochem 19: 263-275.

LABATo MA, BRIGGS RT (1985) Cytochemical localization of hydrogen peroxide generating sites in the rat thyroid gland. Tiss Cell 17: 889-900.

LANGer GA, Frank JS (1972) Lanthanum in heart cell culture. Effect on calcium exchange correlated with its localization. J Cell Biol 54: 441-455.

LuCchesi BR, MulLANE KM (1986) Leukocytes and ischemia-induced myocardial injury. Ann Rev Pharmacol Toxicol 26: $201-224$.

Mezon B, Balley LE (1975) Prevention of relaxation by lanthanum in the kitten heart. J Mol Cell Cardiol 7: 41 7-425. Myers CL, Weiss SJ, Kirsh MM, Shepard BM, Shlafer M (1986) Effects of supplementing hypothermic cardioplegia solutions with catalase, superoxide dismutase, allopurinol or deferoxamine on functional recovery of globally-ischemic and reperfused hearts. J Thorac Cardiovasc Surg 91: 281-289.

Myers CL, Weiss SJ, Kirsh MM, Shlafer M (1985) Involvement of hydrogen peroxide and hydroxyl radical in the "oxygen paradox": reduction of enzyme leakage by catalase, allopurinol or deferoxamine, but not by superoxide dismutasc. J Mol Cell Cardiol 17: 675-684.

Rechardt L, Hervonen H (1985) Cytochemical demonstration of adenylate cyclase activity with cerium histochemistry. Histochemistry 82: 501-505.

Robinson JM, Karnovsky MJ (1983a) Ultrastructural localization of 5'-nucleotidase in guinea pig neutrophils based upon the use of cerium as a capturing agent. J Histochem Cytochem 31: 1190-1196.

RoBinson JM, KARNOVSKY MJ (1983b) Ultrastructural localization of several phosphatases with cerium. J Histochem Cytochem 31: 1197-1208.

Rubanyi GM (1988) Vascular effects of oxygen-derived free radicals. Free Rad Biol Med 4: 107-120

SANBORN WG, LANGER GA (1970) Specific uncoupling of excitation and contraction in mammalian cardiac tissue by lanthanum. J Gen Physiol 56: 191-217.

Schulze W, Will-Shahab L, KütTner I (1986) Cytochemical localization of adenylate cyclase activity in heart tissue with cerium. Acta Histochem 80: 101-110. 
Shlafer M, Kane, PF, Kirsh MM (1982a) Superoxide dismutase plus catalase enhances the efficacy of hypothermic cardioplegia to protect the globally ischemic, reperfused heart. J Thorac Cardiovasc Surg 83: 830-839.

Shlafer M, Kane PF, Wiggins VY, Kirsh MM (1982b) Possible role for cytotoxic oxygen metabolites in the pathogenesis of cardiac ischemic injury. Circulation 66: I-85-I-92.

Shlafer M, Myers CL, Adxins S (1987) Mitochondrial hydrogen peroxide generation and artivities of glutathione peroxidase and superoxide dismutase following global ischemia. J Mol Cell Cardiol 19; 1195-1206.

Vandeplassche G, Hermans C, Thoné F, Borgers M (1989) Mitochondrial hydrogen peroxide generation by NADHoxidase activity following regional myocardial ischemia in the dog. $\mathrm{J}$ Mol Cell Cardiol 21: 383-392.

Veenius M, Wendelaar Bonga SE (1979) Gytochemical localization of catalase and several hydrogen peroxideproducing oxidases in the nucleoids and matrix of rat liver peroxisomes. Histochem J 11: 561-572.

Vissers MCM, DAy WA, Winterbourn CG (1985) Neutrophils adherent to a nonphagocytosable surface (glomerular basement membrane) produce oxidants only at the site of attachment. Blood 66: 161-166.

WAJNER M, HARkNess RA (1989) Distribution of xanthine dehydrogenase and oxidase activities in human and rabbit tissues. Biochim Biophys Acta 991: 7984.

WARREn JS, Kunkel RG, Simon RH, Johnson KJ, WARD PA (1989) Ultrastructural cytochemical analysis of oxygen radical-mediated immunoglobulin $A$ immune complex induced lung injury in the rat. Lab Invest 60: $651-658$.

Wozencraft AO, Croft SL, Sayers G (1985) Oxygen radical release by adherent cell populations during the initial stages of lethal rodent malarial infection. Immunology 56: 523-531. 